\title{
Frequency of Common Factors Leading to Leukocoria in Pediatric Age Group at Tertiary Care Eye Hospital: An Observational Study
}

\author{
Rizwana Dargahi ${ }^{1}$, Abdul Haleem ${ }^{1}$, Darikta Dargahi $\mathrm{S}^{1}$ and Muhammad Faisal Fahim ${ }^{2 *}$ \\ ${ }^{1}$ Department of Ophthalmology, Shaheed Mohtarma Benazir Bhutto Medical University, Pakistan \\ ${ }^{2}$ Department of Research \& Development, Al-Ibrahim Eye Hospital, Pakistan
}

Submission: November 27, 2017; Published: January 19, 2018

*Corresponding author: Muhammad Faisal Fahim, M.Sc. (Statistics), Statistician, Department of Research \& Development, Al-Ibrahim Eye Hospital, Isra postgraduate Institute of Ophthalmology, Karachi, Pakistan, Tel: 0092-346-3160827; Email: faisalfahim88@hotmail.com

\begin{abstract}
Objective: To know the frequency of common factors leading to leukocoria in pediatric age group at a tertiary care eye hospital.

Materials \& methods: This was across sectional observational study carried out at Pediatric department, Al-Ibrahim eye hospital Karachi from February to July 2016. All patients younger than 10 years who presented with leukocoria were included. The excluding criteria were previous history of trauma and ocular surgery. Systemic as well as ocular examination and relevant investigations was done to know cause of leukocoria. B. Scan was done in all the cases. If needed X-ray chest, CT scan \& MRI orbit was done for confirming diagnosis. SPSS version 20.0 was used to analyzed data.

Results: In our country congenital cataract is the most common cause of leukocoria which comprises about $77.3 \%$ (133/172) which is treatable. $2^{\text {nd }}$ common cause was persistent fetal vasculature comprises $8.1 \%$ (14/172). Retinoblastoma was observed in 5.8\% (10/172), Coats disease in $4.7 \%(08 / 172)$ and Retinal detachment in 4.1\% (7/172).Out of 172 cases, 100(58.1\%) were male and 72(41.9\%) were female. Family history of leukocoria was observed in $25.6 \%$ cases. $77.1 \%$ percent of the patients who presented with leukocoria had congenital cataract (61 unilateral and 72 bilateral). Other causes included retinoblastoma in 5.8\% (7 unilateral and 3 bilateral), retinal detachment 4.1\% (all were unilateral), persistent hyperplastic primary vitreous $8.1 \%$ (all were unilateral), and Coats' disease 4.7\% (01 was bilateral and other were unilateral).

Conclusion: Leukocoria in children demands immediate attention because a significant number of children have pathology that either threatens life or causes permanent visual disability. People should be made aware of it. General practitioner, print and electronic media for early diagnosis and treatment.
\end{abstract}

Keywords: Leukocoria; Congenital cataract; Retinoblastoma; Persistent hyperplastic primary vitreous

\section{Introduction}

The term leukocoria means "white pupil" (from the Greek "leukos" meaning white and "kore" meaning pupil) and it is the name given to clinical finding of white pupillary reflex [1]. Normal pupillary color is back in young and grey in old age. It can be the initial manifestation of wide spectrum of intraocular and systemic disease process. It can be caused by abnormalities in the lens (e.g. cataract) vitreous (e.g. hemorrhage) or retina (e.g. retinoblastoma) [2]. Leukocoria in infants is always a danger signal, members of immediate family circle are most likely to notice the first sign, the general practitioner, pediatrician or general ophthalmologist are first to be consulted [3].

Several eye problems in children are first discovered because they cause a white or opaque pupil [4]. Congenital cataract, retinoblastoma, retinal detachment, persistent fetal vasculature and coats disease all may be first discovered by observing that the child has white or opaque pupil. The variety and scope of these various eye problems underscores the importance of discovering a white pupil in an infant [5]. Various diseases with very different pathology can lead to white pupillary reflex in children [6]. Leukocoria demands immediate attention as it may not online endanger patient's vision but also his life, depending on the lesion, the pupil may appear normal in room light but have no red reflex on ophthalmoscopy [7].

Following diseases have shown to cause Leukocoria [8]. Congenital Cataract 60\% (42\% bilateral, 18\% unilateral), Retinoblastoma 18\%. (7\% bilateral, 11\% unilateral), Retinal detachment $4.2 \%$ (1.4\%bilateral, $2.8 \%$ unilateral), Persistent Fetal Vasculature $4.2 \%$ (unilateral usually) and Coats disease 
$4.2 \%$ (unilateral usually). The rationale of study is to find the magnitude of common causes of leukocoria in children visiting Al-Ibrahim Eye hospital Karachi, so that the strategies could be made for early diagnosis and prompt treatment in order to reduce morbidity and mortality. The aim of this study was to know the frequency of common factors leading to leukocoria in pediatric age group.

\section{Material and Methods}

This was across sectional observational study carried out at Pediatric department, Al-Ibrahim eye hospital Karachi from February to July 2016. All patients younger than 10 years who presented with leukocoria were included. The excluding criteria were previous history of trauma and ocular surgery.

Systemic as well as ocular examination and relevant investigations was done to know cause of leukocoria. B.S can was done in all the cases. If needed X-ray chest, CT scan \& MRI orbit was done for confirming diagnosis. Ocular examination including visual acuity, tonometry, torch examination, slit lamp examination and ophthalmoscopy under G/A was done (under supervision). Visual Acuity cannot be taken in very young children, so relay on density and morphology of cataract. Common causes of Leukocoria in children up to 10 years of age are Congenital Cataract, Retinoblastoma, Persistant fetal, vasculature, Coats disease and Retinal detachment. In young child complete history was taken from parents and complete ocular examination was done. In un-cooperative and very young child, Examination under anesthesia (EUA) was done. CT Scan and MRI was done in few patients where it was indicated.

\section{Data analysis}

Statistical analysis was done through the software Statistical package for social sciences (SPSS) version 20.0. Continuous variables were presented as Mean $\pm S D$. All categorical variables were presented as frequency and percentages. Chi square test was applied to see the significance between the variables such as age and gender were compared with common factors leading to leukocoria. P-value $\leq 0.05$ was considered to be statistically significant.

\section{Results}

A total of 172 patients with leukocoria were included in this study. Age distribution of the patients is presented in Figure 1. The median age of the patients was $60(\mathrm{IQR}=60)$ months (Table 1). Out of 172 cases, $100(58.1 \%)$ were male and $72(41.9 \%)$ were female as shown in Figure 1. Family history of leukocoria was observed in $25.6 \%$ cases as shown in Figure 2. The most common factors leading to leukocoria in pediatric patients was Cataract i.e. $77.3 \%$ (133/172). Persistant fetal vasculature was observed in $8.1 \%(14 / 172)$ cases, Retinoblastoma 5.8\% (10/172), Coats disease $4.7 \%$ (8/172) and Retinal detachment 4.1\% (7/172) as presented in Figure 3.

Cataract was significantly high in 6 to 10 years of age as compare to 1 to 5 years and below 1 years of age patients $(p=0.005)$.
Retinoblastoma was significantly high in 1 to 5 years of age as compare to 6 to 10 years of age $(\mathrm{p}=0.035)$. Persistent fetal vasculature was significantly high in less than 1 years of age as compare to higher age groups. Retinal Detachment, coats disease were not significant among the groups (Table 2). Cataract, persistant fetal vasculature, retinoblastoma, coats disease, retinal detachment were not significant between groups as presented in Table 3 .

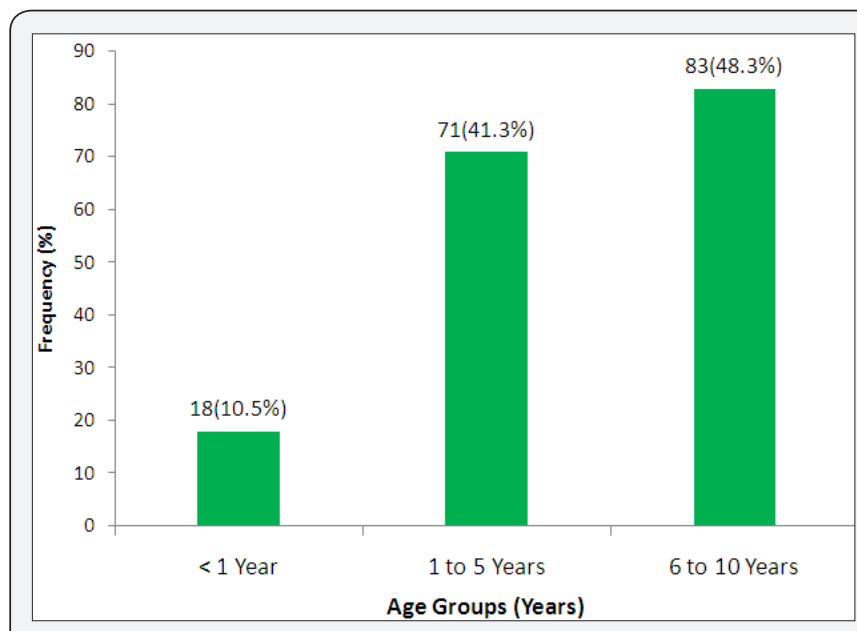

Figure 1: Bar Graphing Showing Age Distribution of the Patients ( $\mathrm{N}=172$ ).

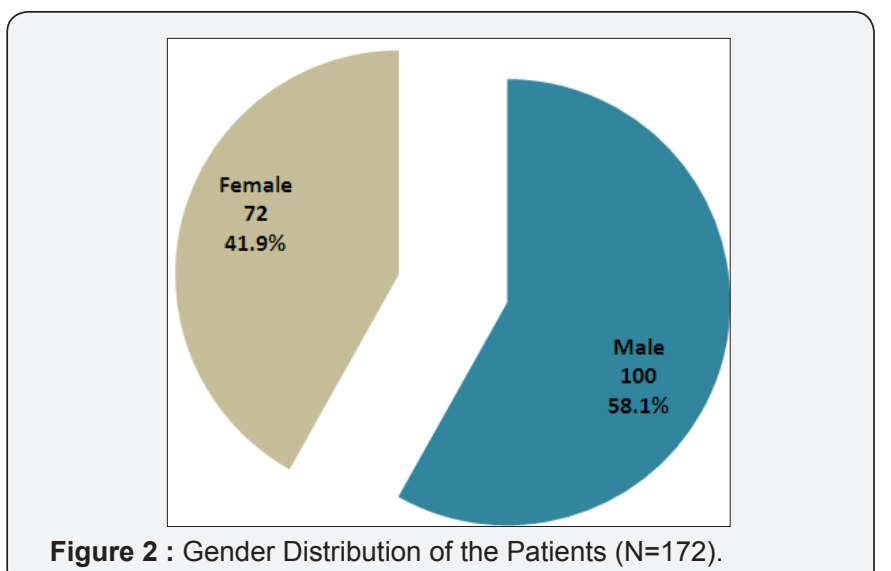

Figure 2 : Gender Distribution of the Patients $(\mathrm{N}=172)$.

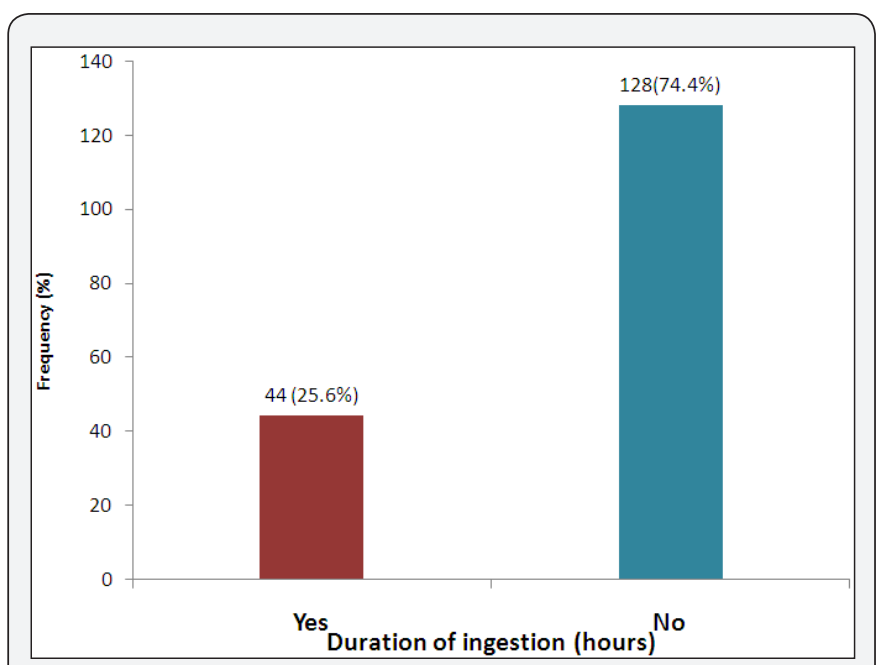

Figure 3 : Family History of Leukocoria $(\mathrm{N}=172)$. 


\section{Biostatistics and Biometrics Open Access Journal}

Table 1: Descriptive Statistics of Patients.

\begin{tabular}{|c|c|}
\hline Variables & Age (Months) \\
\hline Mean \pm SD & $65.28 \pm 37.45$ \\
\hline $95 \%$ CI & $59.64-70.91$ \\
\hline Median (IQR) & $60(60)$ \\
\hline Max- Min & 120 to 1 \\
\hline Range & 119 \\
\hline
\end{tabular}

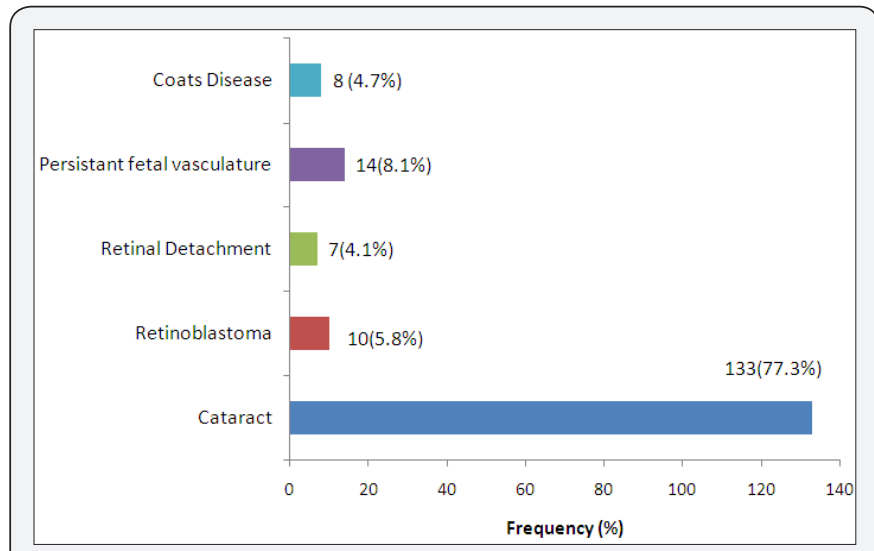

Figure 4 : Frequency of Common Factors Leading to Leukocoria in Paediatric Patients ( $\mathrm{N}=172)$.

Table 2 : Common Factors Leading to Leukocoria in Pediatric Patients with Respect to Age Groups (N=172).

\begin{tabular}{|c|c|c|c|c|}
\hline \multirow{2}{*}{$\begin{array}{c}\text { Common Factors Leading } \\
\text { to Leukocoria }\end{array}$} & \multicolumn{3}{|c|}{ Age Groups } & \multirow{2}{*}{ P-Value } \\
\cline { 2 - 5 } & $<\mathbf{1}$ Years n=18 & $\mathbf{1}$ to 5 Years n=71 & $\mathbf{6}$ to 10 Years n=83 & 0.005 \\
\hline Cataract & $13(72.2 \%)$ & $47(66.2 \%)$ & $73(88 \%)$ & 0.035 \\
\hline Retinoblastoma & $0(0 \%)$ & $8(11.3 \%)$ & $2(2.4 \%)$ & 0.228 \\
\hline Retinal Detachment & $0(0 \%)$ & $5(7 \%)$ & $2(2.4 \%)$ & 0.002 \\
\hline Persistent fetal vasculature & $4(22.2 \%)$ & $9(12.7 \%)$ & $1(1.2 \%)$ & 0.630 \\
\hline Coats Disease & $1(5.6 \%)$ & $2(2.8 \%)$ & $5(6 \%)$ & \\
\hline
\end{tabular}

${ }^{*}$ Chi-Square test applied.

Table 3: Common Factors Leading to Leukocoria in Pediatric Patients with Respect to Gender $(\mathrm{N}=172)$.

\begin{tabular}{|c|c|c|c|}
\hline \multirow{2}{*}{$\begin{array}{c}\text { Common Factors Leading to } \\
\text { Leukocoria }\end{array}$} & \multicolumn{2}{|c|}{ Gender } & \multirow{2}{*}{ P-Value } \\
\cline { 2 - 4 } & Male $\mathbf{n = 1 0 0}$ & Female $\mathbf{n = 7 2}$ & 0.90 \\
\hline Cataract & $77(77 \%)$ & $56(77.8 \%)$ & 0.23 \\
\hline Retinoblastoma & $4(4 \%)$ & $6(8.3 \%)$ & 0.13 \\
\hline Retinal Detachment & $6(6 \%)$ & $1(1.4 \%)$ & 0.62 \\
\hline Persistent fetal vasculature & $9(9 \%)$ & $5(6.9 \%)$ & 0.63 \\
\hline Coats Disease & $4(4 \%)$ & $4(5.6 \%)$ & \\
\hline
\end{tabular}

${ }^{*}$ Chi-Square test applied.

\section{Discussion}

Childhood Leukocoria is a serious problem but no study has been conducted so far in this subject. This study was carried out to evaluate relative incidence of different aetiological factors leading to Leukocoria in children upto 10 years of age, so that we may concentrate and direct health resources to the problem which is more common in our society rather than to depend on the statistical data from aboard. Relative incidence of different diseases lead to leukocoria may differ from those mentioned in literature from abroad. The cause which is rare in other country may be more common in our country.

Common causes of Leukocoria in children upto 10 years of age are Congenital Cataract, Retinoblastoma, Persistent fetal vasculature, Coats disease, Retinal detachment. Out of 172 cases, $100(58.1 \%)$ were male and $72(41.9 \%)$ were female as shown in
Figure 2. Family history of leukocoria was observed in $25.6 \%$ cases as shown in Figure 3. As reported in Parulekar MV et al. [9] Retinoblastoma is the most common pediatric intraocular tumor. Recent studies show increase in the incidence of retinoblastoma. Delay in diagnosis leads to increase in mortality and morbidity rate [9]. Othman IS showed in his study, Leukocoria may be revealed in off-axis flash photographs, taking by the parents. Other manifestations of retinoblastoma include: strabismus, poor vision, nystagmus, orbital inflammation, excess watering. Ultrasonography, funduscopy, fluorescein angiography, MRI and CT-scan can be used to confirm the diagnosis [10]. Tuli SY et al. [11] reported that Treatment depends on the size of the tumor and its laterality, systemic status and metastasis of the tumor [11].

The most common factors leading to leukocoria in pediatric patients was cataract i.e. $77.3 \% \quad(133 / 172)$. Persistant 
fetal vasculature was observed in $8.1 \%$ (14/172) cases, retinoblastoma $5.8 \%(10 / 172)$, coats disease $4.7 \%(8 / 172)$ and retinal detachment $4.1 \%(7 / 172)$ as presented in Figure 4. Cataract was significantly high in 6 to 10 years of age as compare to 1 to 5 years and below 1 years of age patients $(p=0.005)$. Retinoblastoma was significantly high in 1 to 5 years of age as compare to 6 to 10 years of age $(p=0.035)$. Persistent fetal vasculature was significantly high in less than 1 years of age as compare to higher age groups. Retinal Detachment, coats disease were not significant among the groups. General Practiconer (Gps), opticians, lady health workers (LHW) should play a key role in our health system. At present many of them are unaware of common health problems. It will be logical to commence training programs for Gps, opticians and lady health workers, to apprise them of the common eye ailments and their proper referral. Early diagnosis and treatment of known causes of white pupil is important as it is vision as well as life threatening.

\section{Conclusion}

Leukocoria in children demands immediate attention because a significant number of children have pathology that either threatens life or causes permanent visual disability. People should be made aware of it. General practitioner, print and electronic media for early diagnosis and treatment. Leukocoria is a vision as well as life threatening condition. People should be made aware of it.

\section{Recommendations}

It is suggested that public education for awareness of white pupil should be carried out on large scale, all the audio-visual media like seminar, newspapers, radio and TV should be made use of for this purpose. Congenital cataract is the most common cause of "white pupil" which is vision threatening and other common cause retinoblastoma, which as well as life threatening condition.

Genetic counseling is an important part of overall management of "white pupil" and should be given weight. The offspring and sibling with hereditary white pupil should be examined thoroughly (ocular as well as systemic examination) every 3 to 4 months for first 2 to 4 years of life to permit early detection and treatment. Early diagnosis and treatment of known causes of white pupil is important as it is vision as well as life threatening.

\section{References}

1. Kaufman PL, Saunders RA (2011) Approach to a child with leukocoria.

2. Canzano JC, Handa JT (1999) Utility of pupillary dilation for detecting leukocoria in patients with retinoblastoma. Pediatrics 104(4): e44.

3. Gitter KA, Meyer D, White RH, Ortolan G, Sarin LK (1968) Ultrasonic aid in evaluation of leukocoria. Am J Ophthalmol 65(2): 190-195.

4. Balmer A, Munier F (2007) Diagnosis of leukocoria and strabismus, First presenting sign of retinoblastoma. Clin Ophthalmol 1(4): 431439.

5. Hammura S, Zasshi NGG (2001) Review leukocoria 105: 495-510.

6. Kadom N, Raymond W (2008) Amer Jour of Roentgenology 191: 40-44.

7. Mattas S (1988) Leukocoria in infants and children. Ophthalmologist Maxicare, inc. Future Reflection Fall, 7.

8. Haider S, Quershi, Ali A (2008) Leukocoria in children. J Pediatric Ophthalmol Strabismus 45(3): 179-180.

9. Parulekar MV (2010) Retinoblastoma-current treatment and future direction. Early Hum Dev 86(10): 619-625.

10. Othman IS (2012) Retinoblastoma major review with updates on Middle East management protocols. Saudi J Ophthalmol 26(2): 163175 .

11. Tuli SY, Giordano BP, Kelly M, Fillipps D, Tuli SS (2013) Newborn with an absent red reflex. J Pediatr Health Care 27(1): 51-55.

\section{Your next submission with Juniper Publishers} will reach you the below assets

- Quality Editorial service

- Swift Peer Review

- Reprints availability

- E-prints Service

- Manuscript Podcast for convenient understanding

- Global attainment for your research

- Manuscript accessibility in different formats ( Pdf, E-pub, Full Text, Audio)

- Unceasing customer service

Track the below URL for one-step submission https://juniperpublishers.com/online-submission.php 